\title{
МЕТОДИКА ОПРЕДЕЛЕНИЯ ТИПА РОСТА ЛИЦЕВОГО СКЕЛЕТА
}

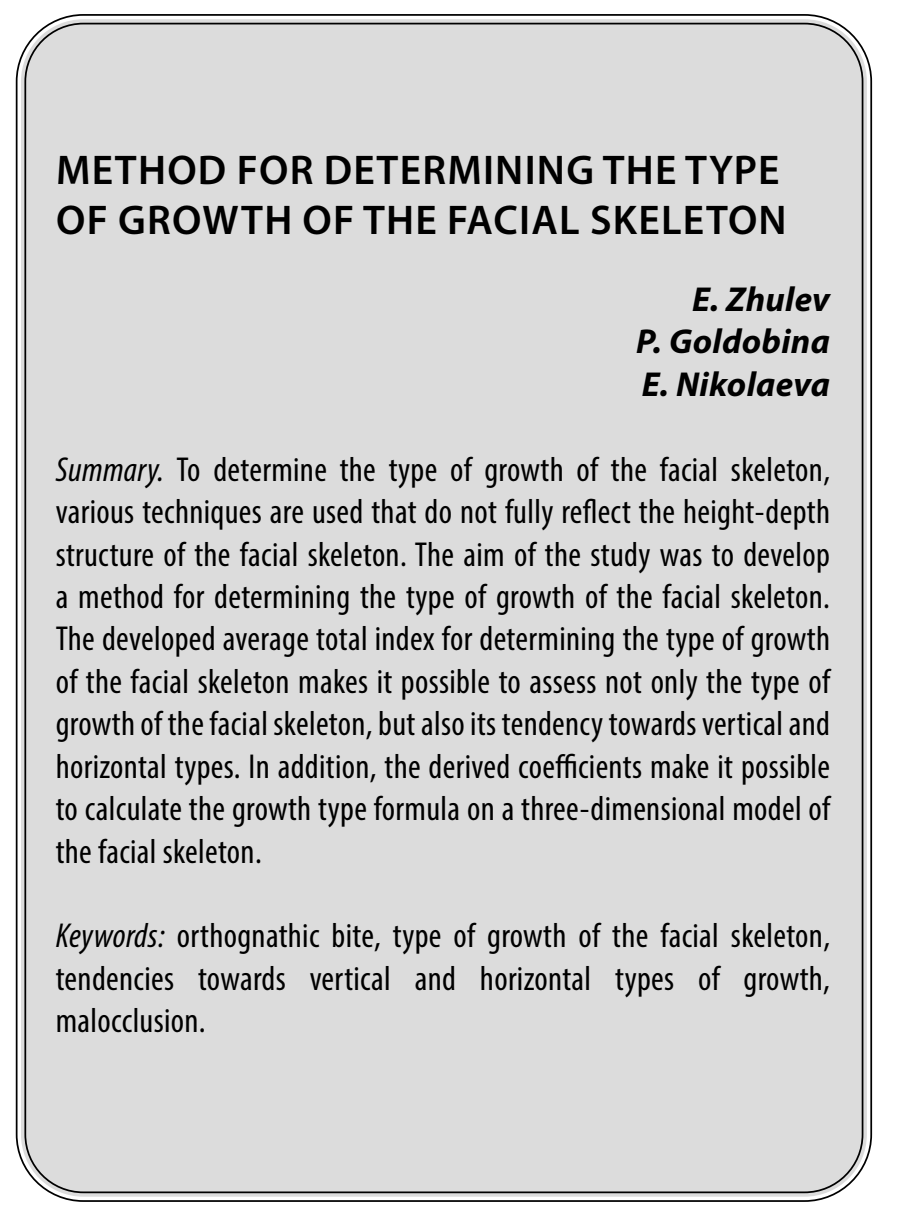

\section{Актуа^ьность}

C целью определения типа роста лицевого скелета используются различные методики. Так Bjork A. (1966) определил три направления роста нижней челюсти: вертикальное, горизонтальное и нейтральное. Распространенность различных типов роста по данным разных авторов существенно отличается: вертикального - от 2,9 до 14\%, горизонтального - от 12 до 26\%. Есть данные, подтверждающие взаимосвязь горизонтального и вертикального типов роста с различными зубочелюстными аномалиями $[1,2,4,5,6,7,8]$.

Тип рост лицевого скелета Персин Л.С. предлагает определять на основании серии угловых измерений и соотношения передней и задней высоты лица [4], а Фадеев Р.А. проводит оценку направления роста лицевого отдела черепа с помощью двух углов, характеризующих наклон нижней челюсти к основанию черепа (Pm/Pb) и ось переднее-заднего вращения (n-s-gn)
Жулев Евгений Николаевич

Д.м.н., профессор, ФГБОУ ВО «Приволжский Исследовательский Медицинский Университет» Минздрава России (г. Нижний Новгород)

Голдобина Полина Владимировна

Аспирант, ФГБОУВО «Приволжский Исследовательский Медицинский Университет» Минздрава России (г. Нижний Новгород) pelagold_nn.52@mail.ru

Николаева Елена Юрьевна К.м.н., доцент, ФГБОУ ВО «Приволжский Исследовательский Медицинский Университет» Минздрава России (г. Нижний Новгород)

Аннотация. Для определения типа роста лицевого скелета используются различные методики, не отражающие в полной мере высотно-глубинное строение лицевого скелета. Целью исследования явилась разработка методики определения типа роста лицевого скелета. Разработанный средний суммарный индекс для определения типа роста лицевого скелета позволяет оценить не только тип роста лицевого скелета, но и его тенденции к вертикальному и горизонтальным типам. Кроме того, выведенные коэффициенты позволяют проводить расчет формулы типа роста на трехмерной модели лицевого скелета.

Ключевые слова: ортогнатический прикус, тип роста лицевого скелета, тенденции к вертикальному и горизонтальному типам роста, аномалии прикуса.

[7]. По мнению Хорошилкиной Ф.Я., угол NSL-ML, равный $35^{\circ}$ или больше, характеризует вертикальный тип роста нижней челюсти, а равный $32^{\circ}$ и менее - горизонтальный [8].Однако данные методики не отражают в полной мере высотно-глубинное строение лицевого скелета. По мнению Жулева Е.Н. [2], именно нарушение пропорциональности развития его отдельных структур приводит к изменению направления роста лицевого скелета. Так, преобладание глубины лица над высотой характеризует горизонтальный тип роста, а преобладание высоты над глубиной - вертикальный. При данных вариантах происходит нарушение развития лицевого скелета в поперечно-продольном направлениях, затрагивающее наибольшее количество структур черепно-лицевого комплекса.

Таким образом, разработка методики определения типа роста лицевого скелета на основании изучения особенностей его высотно-глубинного строения является актуальным и имеет большое значение для диагностики и лечения аномалий зубочелюстной системы. 


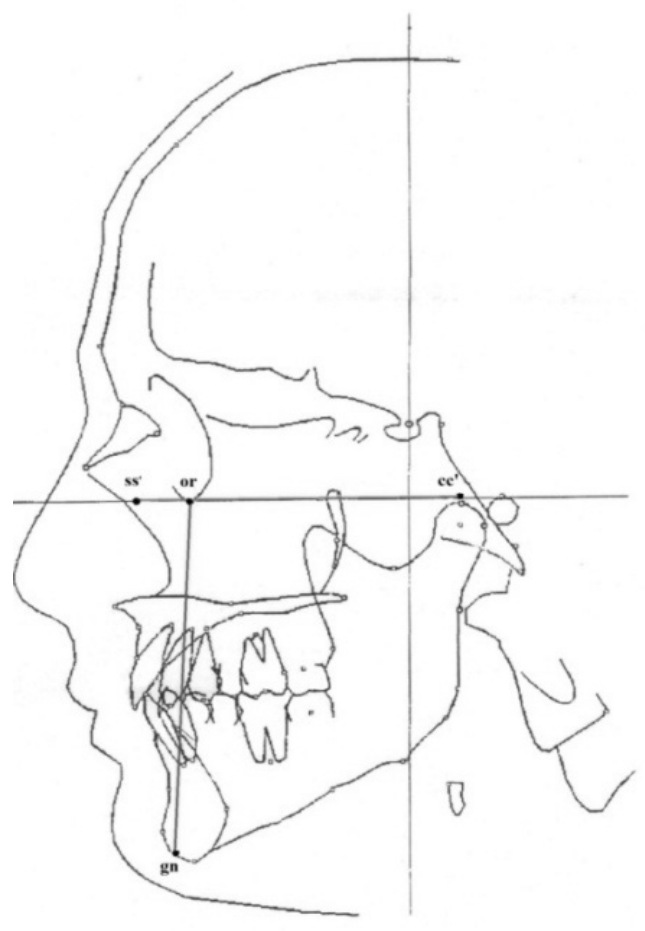

Рис. 1. Высотно-глубинный индекс Bimler

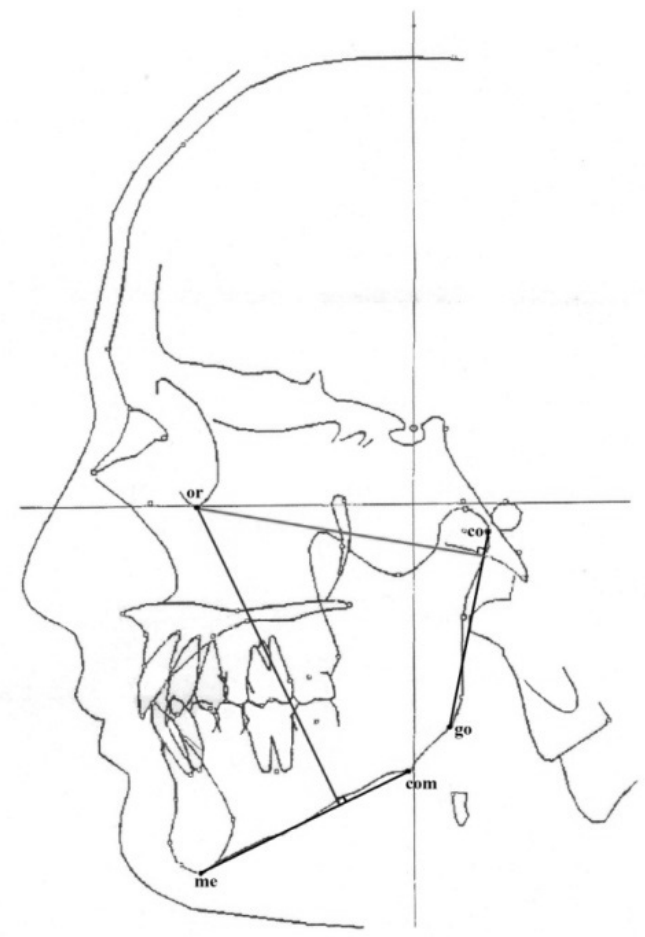

Рис. 3. Соотношение глубины и высоты лица

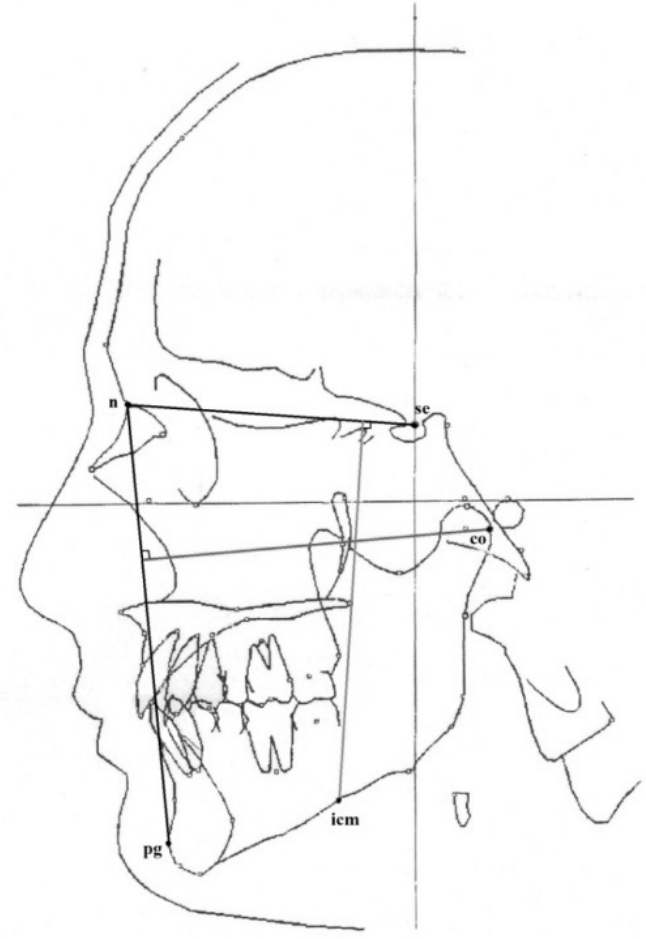

Рис. 2. Соотношение общей глубины и высоты лица

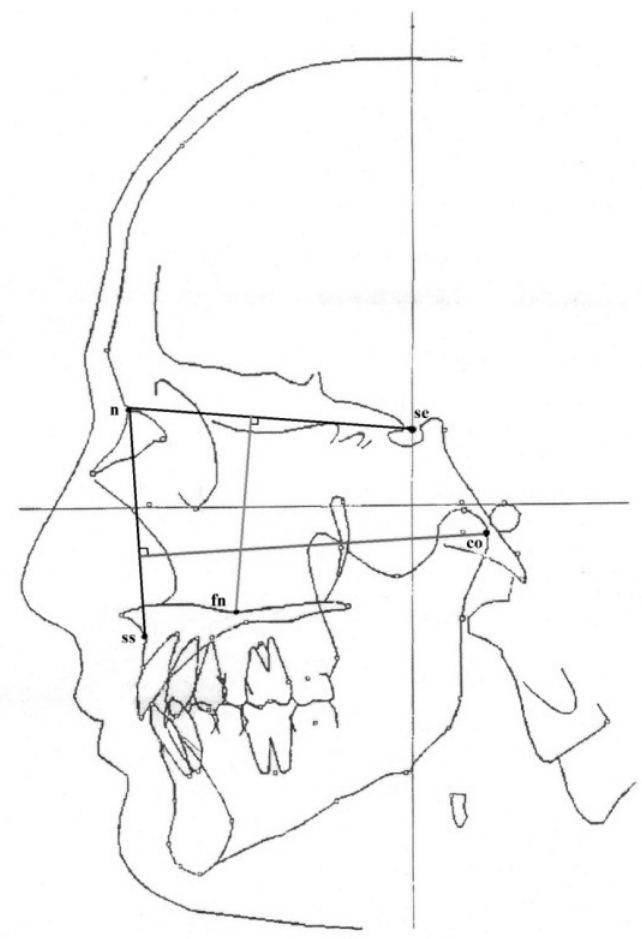

Рис. 4. Соотношение глубины и высоты средней зоны лица 
Таблица 1. Рентгеноцефалометрические параметры для изучения различных типов роста лицевого скелета

\begin{tabular}{|c|c|c|c|c|}
\hline \multirow{2}{*}{ № } & \multirow{2}{*}{$\begin{array}{l}\text { Индексы определения типа роста } \\
\text { лицевого скелета }\end{array}$} & \multicolumn{3}{|c|}{ Тип роста лицевого скелета } \\
\hline & & нейтральный & горизонтальный & вертикальный \\
\hline 1 & $(o r-g n) * 100 / s s^{\prime}-c c^{\prime}$ & $110,0 \pm 9,0$ & $<101$ & $>119$ \\
\hline 2 & co $(n-p g)^{*} 100 /$ icm(n-se) & $88,0 \pm 6,0$ & $>94$ & $<82$ \\
\hline 3 & or $($ co-go) $* 100 /$ or (me-com) & $90,5 \pm 4,5$ & $>95$ & $<86$ \\
\hline 4 & $\operatorname{co}(n-s s) * 100 / f n(n-s e)$ & $170,0 \pm 10$ & $>180$ & $<160$ \\
\hline 5 & $\begin{array}{l}\text { ss }(\text { se-ram) } * 100 / f n(n-s e)+f n(m e- \\
\text { com) }\end{array}$ & $70,5 \pm 4,5$ & $>75$ & $<66$ \\
\hline
\end{tabular}

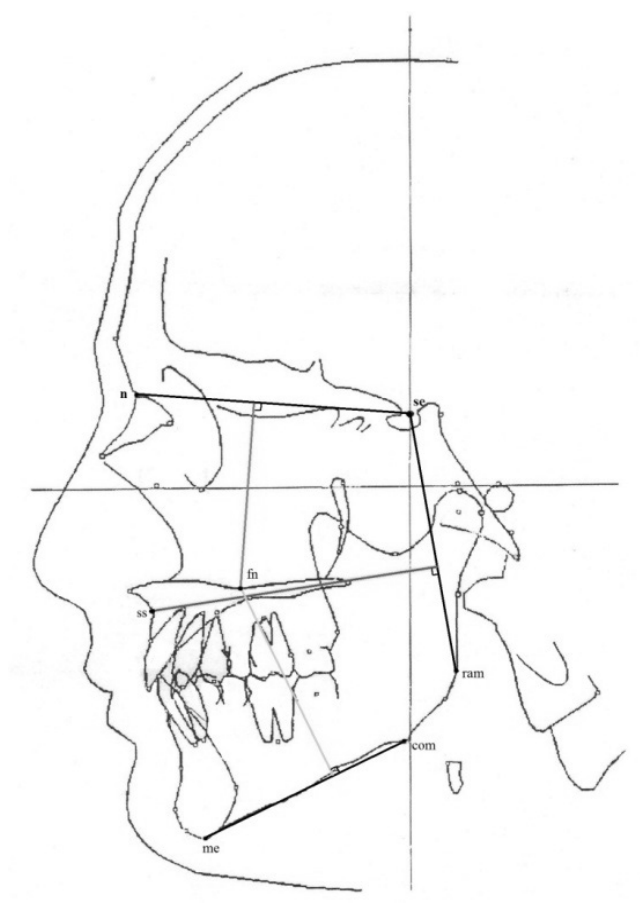

Рис. 5. Соотношение глубины средней зоны лица к высоте средней зоны и высоте среднего отдела гнатической части

\section{Цель $\triangle$ анного \\ исслеАования}

Разработка новой методики определения типа роста лицевого скелета.

\section{Материалы и метомы}

Предложенная нами методика определения типа роста лицевого скелета состоит из 2 этапов. На первом проводится оценка 5 параметров, отражающих высотно-глубинное строение лицевого скелета [2]. Для этого сначала рассчитываются пять соотношений по следующим формулам:

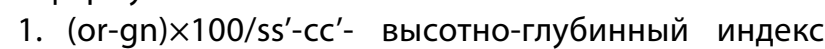
Bimler (Рис. 1),

2. co(n-pg) $\times 100 / \mathrm{icm}(\mathrm{n}-\mathrm{se})$ - соотношение общей глубины и высоты лица (Рис. 2),

3. $\operatorname{or}($ co-go) $\times 100 /$ or(me-com) - соотношение глубины и высоты лица от нижнего края орбиты 
Таблица 2. Интервалы значения суммарного среднего индекса для определения типа роста лицевого скелета.

\begin{tabular}{|c|c|c|c|c|c|}
\hline & \multicolumn{5}{|c|}{ Типы роста лицевого скелета } \\
\hline & $\begin{array}{l}\text { Вертикальный тип } \\
\text { роста }\end{array}$ & $\begin{array}{l}\text { Тенденция } \\
\text { к вертикальному } \\
\text { типу роста }\end{array}$ & $\begin{array}{l}\text { Нейтральный тип } \\
\text { роста }\end{array}$ & $\begin{array}{l}\text { Тенденция } \\
\text { к горизонтальному типу } \\
\text { роста }\end{array}$ & $\begin{array}{l}\text { Горизонтальный тип } \\
\text { роста }\end{array}$ \\
\hline $\begin{array}{l}\text { Значения } \\
\text { суммарного } \\
\text { индекса }\end{array}$ & $<102,31$ & $100,92-104,51$ & $104,51-107,59$ & $107,60-109,57$ & $>109,57$ \\
\hline
\end{tabular}

Таблица 3. Распределение типов роста лицевого скелета по суммарному индексу при ортогнатическом прикусе

\begin{tabular}{|l|l|l|l|l|}
\hline & \multicolumn{2}{|l|}{ Типы роста лицевого скелета } \\
& Вертикаль-ный & $\begin{array}{l}\text { Тенденция } \\
\text { к вертикаль- } \\
\text { ному }\end{array}$ & $\begin{array}{l}\text { Горизонталь- } \\
\text { ный }\end{array}$ & $\begin{array}{l}\text { Тенденция } \\
\text { к горизонталь- } \\
\text { ному }\end{array}$ \\
\hline $\begin{array}{l}\text { Ортогнатический } \\
\text { прикус }(\mathrm{n}=61)\end{array}$ & $6(9,9 \%)$ & $\begin{array}{l}\text { Нейтраль- } \\
\text { ный }\end{array}$ & $11(18 \%)$ & $11(18 \%)$ \\
\hline
\end{tabular}

Таблица 4. Распределение типов роста лицевого скелета по суммарному индексу у пациентов с различными аномалиями зубочелюстной системы

\begin{tabular}{|l|l|l|l|l|l|}
\multirow{2}{*}{ Вид прикуса } & \multicolumn{2}{|l|}{ Тип роста лицевого скелета } & Горизонтальный & $\begin{array}{l}\text { Тенденция } \\
\text { к горизонтальному }\end{array}$ & Нейтральный \\
\cline { 2 - 6 } & Вертикальный & $\begin{array}{l}\text { Тенденция } \\
\text { к вертикальному }\end{array}$ & $17(47,2 \%)$ & $10(27,8 \%)$ & $6(16,7 \%)$ \\
\hline $\begin{array}{l}\text { Дистальный } \\
\begin{array}{l}\text { рикус } \\
(n=36)\end{array}\end{array}$ & $2(5,5 \%)$ & $1(2,8 \%)$ & $7(46,7 \%)$ & $2(13,3 \%)$ & $2(13,3 \%)$ \\
\hline $\begin{array}{l}\text { Мезиальный } \\
\text { прикус }(n=15)\end{array}$ & $1(6,7 \%)$ & $3(20 \%)$ & $9(47,4 \%)$ & $4(21,1 \%)$ & $4(21,1 \%)$ \\
\hline $\begin{array}{l}\text { Глубокий прикус } \\
(n=19)\end{array}$ & $2(10,4 \%)$ & - & $6(37,5 \%)$ & $4(25 \%)$ & $3(18,75 \%)$ \\
\hline $\begin{array}{l}\text { Открытый прикус } \\
(n=16)\end{array}$ & $1(6,25 \%)$ & $2(12,5 \%)$ & & \\
\hline
\end{tabular}

Таблица 5. Значения критерия Уилкоксона и уровень значимости для индексов формулы определения типа роста лицевого скелета.

\begin{tabular}{|c|c|c|c|}
\hline № & Индексы определения типа роста лицевого скелета & Т-критерий Уилкоксона & Уровень значимости (р) \\
\hline 1 & $\left((\right.$ or-gn $\left.) * 100 / s s^{\prime}-c c^{\prime}\right) п$. & 967 & 0,169 \\
\hline 2 & $\left(\right.$ co $\left.(n-p g)^{*} 100 / i c m(n-s e)\right)$ п. & 755,5 & 0,732 \\
\hline 3 & $(\operatorname{or}(\operatorname{co}-g o) * 100 /$ or (me-com)) п. & 794,5 & 0,980 \\
\hline 4 & $(c o(n-s s) * 100 / f n(n-s e) \sqcap$. & 653 & 0,239 \\
\hline 5 & $($ ss $($ se-ram $) * 100 /(f n(n-s e)+$ fn $($ me-com) $))$ п. & 832 & 0,785 \\
\hline
\end{tabular}


до восходящей ветви и основания нижней челюсти (Рис. 4),

4. $\mathrm{co}(\mathrm{n}-\mathrm{ss}) \times 100 / \mathrm{fn}(\mathrm{n}-\mathrm{se})$ - соотношение глубины и высоты средней зоны лица (Рис. 4),

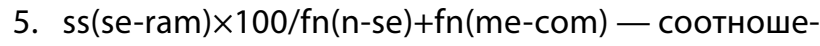
ние глубины средней зоны лица к высоте средней зоны и высоте среднего отдела гнатической части (Рис. 5).

Полученные данные сверяют со значениями, представленными в таблице 1.

На втором этапе с целью создания и проверки эффективности общего индекса типа роста лицевого скелета нами были изучены 61 телерентгенограмма (ТРГ) лиц с ортогнатическим прикусом и 65 компьютерных томограмм (КТ) пациентов с различными аномалиями соотношения зубных рядов.

\section{Результаты исследования}

ТРГ лиц с ортогнатическим прикусом были распределены в порядке убывания от среднего значения суммарного индекса в сторону его минимального и максимального значения. Для этого были изучены средние значения суммы пяти индексов и выведен суммарный средний индекс, характеризующий общий тип роста лицевого скелета (табл. 2.).

С помощью данного индекса были изучены 61 ТРГ пациентов с ортонатическим прикусом и получены следующие данные (табл. 3 .).

Из таблицы 3 видно, что при ортогнатическом прикусе преобладает нейтральный тип роста лицевого скелета $(37,7 \%)$, а тенденции к вертикальному и горизонтальному типам встречаются гораздо реже.

Данный индекс также был рассчитан на 65 КТ пациентов с различными аномалиями зубочелюстной системы (таблица 4).

Распределение аномалий прикуса по типам роста лицевого скелета с помощью общего индекса показало, что тенденции в типах роста лицевого скелета по сравнению с ортогнатическим прикусом меняются. При дистальном и глубоком прикусе наблюдается преобладание горизонтального типа роста. Значительно увеличивается количество пациентов с мезиальным прикусом и тенденцией к вертикальному типу роста лицевого скелета.

Для перевода формулы из 2D TPГ на 3D были проведены расчеты 3D-параметров формулы 65 KT пациентов на трехмерной модели лицевого скелета в программе Dolphin Image с различными типами роста лицевого скелета. На основании полученных результатов были выведены следующие индексы для трехмерной модели: 1,$09 ; 0,9468 ; 0,9909 ; 0,8633 ; 0,9993$.

Таким образом, формула расчета типа роста лицевого скелета на трехмерной модели приобретает следующий вид:

1. $\left((\right.$ or-gn $\left.) * 100 / \mathrm{ss}^{\prime}-\mathrm{cc}^{\prime}\right) * 1,09$.

2. $\left(\right.$ co $\left.(\mathrm{n}-\mathrm{pg})^{*} 100 / \mathrm{icm}(\mathrm{n}-\mathrm{se})\right) * 0,9468$.

3. $($ or (co-go) * 100/or (me-com) $) * 0,9909$.

4. $($ co $(n-s s) * 100 / f n(n-s e)) * 0,8633$.

5. $(\text { ss }(\text { se-ram }) * 100 /(f n(n-s e)+f n(m e-c o m)))^{*} 0,9993$.

Оценка достоверности индексов типа роста по разработанной нами методике на 3D TPГ лицевого скелета проводилась с вероятностью ошибочного признания различий (значимы меньше 0,005).

В таблице 5 приведены значения критерия Уилкоксона и соответствующие ему уровни значимости (p) для каждого индекса формулы определения типа роста лицевого скелета при сравнении результатов оценки типа роста на 2D и 3D модели лицевого скелета.

Таким образом, из таблицы 4 видно, что индексы, полученные при измерении на 2D и 3D ТРГ неразличимы с уровнем значимости $\mathrm{p}<0,005$ ни по одному из признаков. Таким образом, индексы, измеренные на 2D и 3D ТРГ, неразличимы между собой, что свидетельствует о достоверности полученных нами коэффициентов.

\section{Зак^ючение}

Разработанный средний суммарный индекс для определения общего типа роста лицевого скелета позволяет оценить не только тип роста, но и его тенденции к вертикальному и горизонтальным типам. Кроме того, выведенные нами коэффициенты позволяют проводить расчет разработанной нами формулы типа роста на трехмерной модели лицевого скелета.

\section{ЛИТЕРАТУРА}

1. Аболмасов, Н.Г. Ортодонтия: учебное пособие / Н.Г. Аболмасов, Н.Н. Аболмасов. - М.: МЕДпресс-информ, 2008. - 424 с.

2. Жулев, Е.Н.Ортопедическая стоматология: учебник / Е.Н.Жулев.- М.: МИА (Медицинское информационное агентство), 2012.824 с.: ил. 
3. Жулев Е.Н., Николаева Е.Ю., Голдобина П.В. Патент РФ № 2717273/ 19.03.2020 Способ оценки типа роста лицевого скелета [Текст]: пат. 2717273 Рос. Федерация. № 2717273 С1: МПК А61В6/14.

4. Персин, Л.С. Ортодонтия. Диагностика и лечение зубочелюстно-лицевых аномалий и деформаций: учебник / Л.С. Персин [и др.].- М.: ГЭОТАР-Медиа, 2015.- 640 с.: ил.

5. Трезубов, В.Н. Ортодонтия: учебное пособие / В.Н. Трезубов, А.С. Щербаков, РА Фадеев. — М: Медицинская книга, Н. Новгород: Изд-во НГМА, 2001.$148 \mathrm{C.}$

6. Фадеев, Р.А. Выявление корреляционных связей между различными рентгеноцефалометрическими параметрами / Р.А. Фадеев, А.Н. Исправникова // Институт стоматологии. — 2009.— № 2.— С. 22-24.

7. Фадеев, Р.А. Цефалометрическая диагностика зубочелюстных аномалий: учебное пособие / Р.А. Фадеев, В.В. Тимченко, Ю.П. Литовченко; Министерство здравоохранения Российской Федерации, Северо-Западный государственный медицинский университет имени И.И. Мечникова.- Санкт-Петербург: Эко-Вектор, 2017.-92, с.: ил.

8. Хорошилкина, Ф.Я. Соотношение основного направления роста лицевого отдела черепа при физиологической окклюзии, дистоокклюзии и врожденных типах профиля лица / Ф.Я. Хорошилкина, Л.П. Набатчикова, А.Г. Чобанян, А.А. Манучарян // Российский медико-биологический вестник им. Академика И.П. Павлова. — 2011.— № 1.—- С. 128-137.

( Ж Жулев Евгений Николаевич, Голдобина Полина Владимировна ( pelagold_nn.52@mail.ru ), Николаева Елена Юрьевна.

Журнал «Современная наука: актуальные проблемы теории и практики»

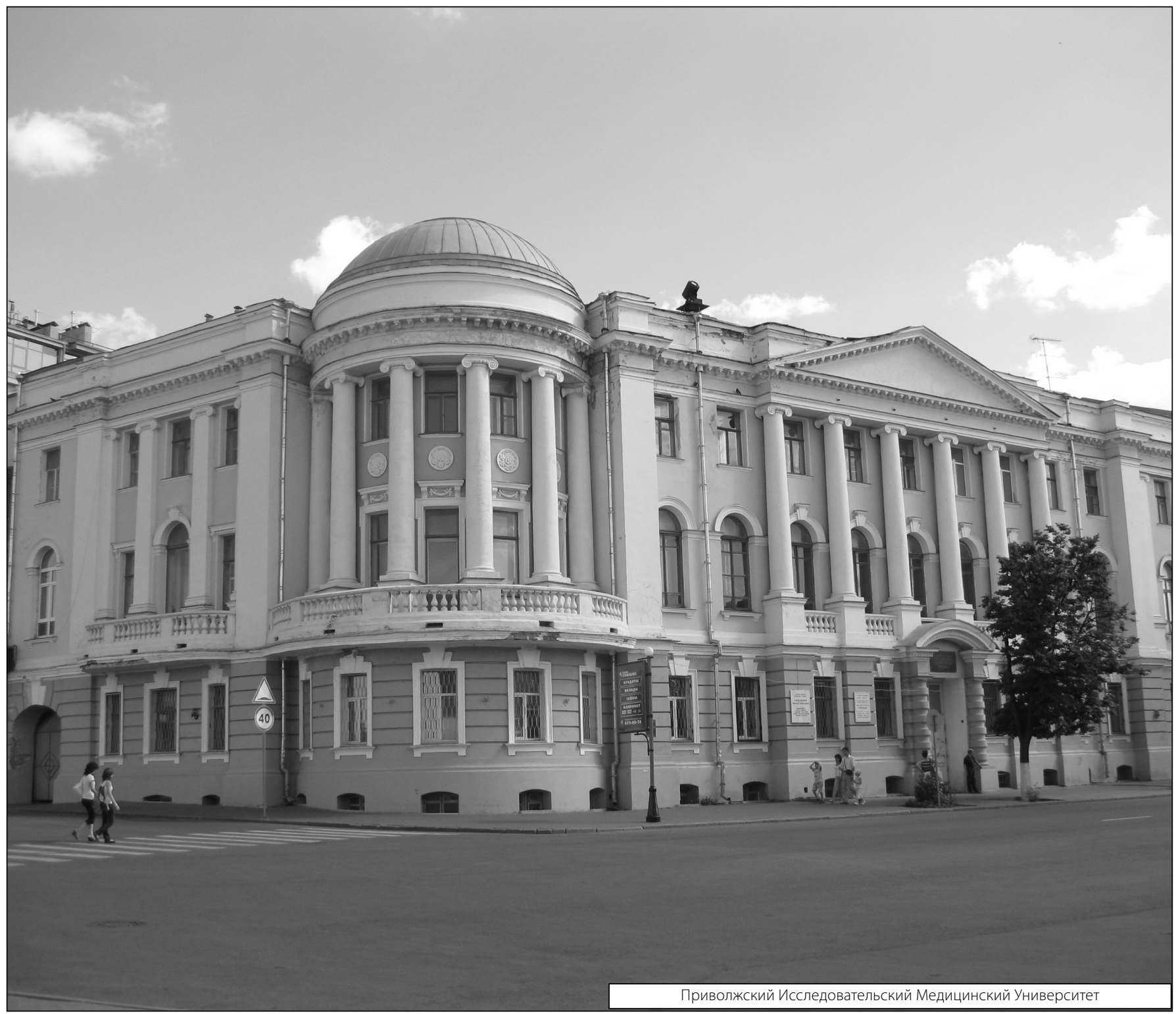

